DOI: https://doi.org/10.24867/03BE19Adzic

\title{
POTENCIJAL KORIŠTENJA GEOTERMALNIH PUMPA NA PODRUČJU GRADA BIJELJINE
}

\section{POTENTIAL OF THE GEOTHERMAL HEAT PUMPS IN BIJELJINA}

\author{
Branko Adžić, Fakultet tehničkih nauka, Novi Sad
}

\begin{abstract}
Oblast - ELEKTROTEHNIKA I RAČUNARSTVO
Kratak sadržaj - U ovom radu predložene su metode eksploatacije geotermalne tople vode na području Bijeljine. Izrađena je tehno-ekonomska analiza grejanja poslovnih zgrada sa geotermalnim toplotnim pumpama $u$ Bijeljini. Predložen je način projektovanja toplotnih pumpi za zagrevanje objekata i izračunat udeo električne energije u tome.
\end{abstract}

Ključne reči: Geotermalna energija, Geotermalne elektrane, Toplotne pumpe

Abstract - This paper proposed ways of exploiting geothermal hot water in Bijeljina. A techno-economic analysis of the heating of business buildings with geothermal heat pumps in Bijeljina was done. The method of designing heat pumps for heating buildings is proposed and electricity share is calculated.

Keywords: Geothermal energy, Geothermal power plants, Geothermal heat pumps

\section{UVOD}

Geotermalni resursi su široko rasprostranjeni u svim delovima sveta, ali je korišćenje nedovoljno prisutno uprkos ekološkim pogodnostima i dobrim energetskim bilansom. Višestruke mogućnosti primene pokazuju da se energetski značaj u proizvodnji toplote i električne energije kontinuirano povećava sa smanjenjem rezervi uglja, nafte i gasa. Upotrebljivost toplotne geotermalne energije se smatra velikom šansom za pripremu potrošne tople vode $u$ domaćinstvima, za distributivni sistem zagrevanja stanova, poslovnih i javnih objekata, a onda i proizvodnih staklenika, plastenika, akvakulturu, sušenje poljoprivrednih proizvoda i mnogih drugih oblasti privređivanja.

U ovom radu će se razmatrati mogućnost primene geotermalne energije za zagrevanje objekata u Bjeljini, ali i udeo električne energije u ovom procesu.

\section{GEOTERMALNA ELEKTRANA}

Prema proračunima do kojih je došla Evropska Komisija za istraživanje energije, toplota Zemljine unutrašnjosti može obezbediti veoma stabilan i dugotrajan izvor energije. Samo jedan kubni kilometar užarene mase može predati $30 \mathrm{MW}$ električne energije u periodu od 30 god.. Da bi se ta energija iskoristila, razvijene su mnoge tehnologije, ali pojednostavljeno mogu se izdvojiti dve vrste

\section{NAPOMENA:}

Ovaj rad proistekao je iz master rada čiji mentor je bio prof. dr Vladimir Katić. korištenja geotermalne energije: Direktno, tj. upotreba vruće vode koja izbija (ili se ispumpa) iz podzemlja ili Indirektno korišćenje geotermalne energije, tj. pretvaranje u električnu energiju (geotermalna elektrana).

Geotermalna elektrana u stvari je kao svaka druga termoelektrana, s tim što se para ne proizvodi gorenjem nekog fosilnog goriva, već se crpi iz zemlje. Vrela voda i para iz dubine zemlje može se koristiti za proizvodnju električne energije tako što se izbuše bunari u zemlji i cevi se spuštaju u vrele bazene sa podzemnom vodom. Vrela voda ili para penje se tim cevima na površinu, gde se dodatno obrađuje $\mathrm{i}$ pod velikim pritiskom vodi na parnu turbinu. Turbina obrće sinhroni generator i generiše se električne energija, koja se zatim sprovodi u elektroenergetski sistem preko prenosnih transformatora.

\section{GEOTERMALNA ENERGIJA NA PODRUČJU GRADA BIJELJINA}

Geotermalni resurs Semberije otkriveni su 1957. godine posle izrade istražne bušotine u Dvorovima kada je došlo do erupcije termalne vode sa temperaturom od $75^{\circ} \mathrm{C}$. Površina rezervoara procenjuje se na oko $2.000 \mathrm{~km}^{2}$, a njegova dubina minimalno $500 \mathrm{~m}$ do $2.500 \mathrm{~m}$, u proseku oko $1.000 \mathrm{~m}$. Dobijeni rezultati utvrđeni su izradom više bušotina, od toga pet dubokih bušotina, dubine od 1.280 2.500 metara urađeno je u Semberiji.

Dosadašnja primena evidentnih resursa je međutim veoma skromna s obzirom da se u Dvorovima iz bušotine koristi samo 7 1/sek termalnih voda pri čemu se $2 / 3$ njene geotermalne energije baca $u$ kanalizaciju jer nema potrošača koji bi tu energiju iskoristili.Samo za toplifikaciju grada Bijeljine u sadašnjoj veličini, postojeća energija je dovoljna za minimalno narednih 200 godina, pod uslovom da se geotermalni sistem ne obnavlja. Pošto je geotermalni sistem obnovljiv, to je perspektiva geotermalne energije na ovom području velika i imaće značajno mjesto u budućem razvoju grada i neposredne okoline.

\section{TOPLOTNE PUMPE}

Toplotne pumpe su uređaji pomoću kojih se toplotna energija iz jedne sredine prenosi u drugu sredinu. Za taj prenos toplotne energije takođe je potrebno da se utroši određena energija koja je nekoliko puta manja od prenete energije (slika 1)

\subsection{Tipovi toplotnih pumpi}

Postoje dva osnovna tipa sistema geotermalnih toplotnih pumpi, GTP s otvorenim i zatvorenim krugom. Ova dva tipa se mogu podeliti na sledeće podsisteme: 


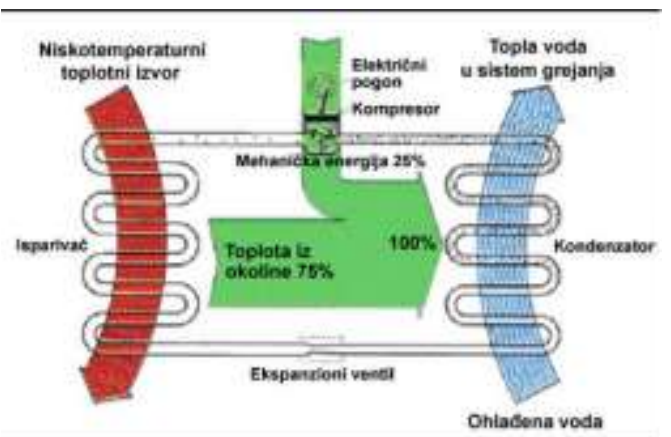

Slika 1. Odnos uložene električne energije i iskorišćene geotermalne energije [2]

1) Sistem sa zatvorenim krugom:

- vertikalan

- horizontalan

- zatvoreni sistem s površinskom vodom

2) Sistem s otvorenim krugom: dve bušotine (proizvodna i utisna, ili izliv)

\subsection{Osnovni delovi toplotne pumpe}

U osnovi, po svojim nazivima i funkciji, skoro sve važne komponente toplotnih pumpi istovetne su sa rashladnim elementima. To su:

- kompresori sa pogonskim motorom,

- izmenjivači toplote,

- sudovi pod pritiskom (separatori, odvajači, skupljači rashladnog fluida),

- automatika,

- armature i cevovodi,

- elektrokomandni uređaji,

- rashladni fluid.

\subsection{Električna snaga i energija za toplotne pumpe}

Za proračun energije dobijene od toplotnih pumpi uzima se obračun potrošnje cirkulacione pumpe kao i samog kompresora toplotne pumpe - $\mathrm{SPFH}_{2}$ sa slike 2 obeleženo crvenom linijom.

Prema tome, dobija se:

$$
\begin{aligned}
& \mathrm{E}_{\mathrm{RES}}=\mathrm{Q}_{\text {upo }}-\mathrm{E}_{\mathrm{S} \_ \text {ven/pumpa }}-\mathrm{E}_{\mathrm{HW}-\mathrm{hp}}=\mathrm{Q}_{\text {upot }} \times(1-1 / \mathrm{SPF}) \\
& \mathrm{Q}_{\text {upo }}=\mathrm{Q}_{\mathrm{H} \_ \text {hp }}+\mathrm{Q}_{\mathrm{W} \_ \text {hp }}
\end{aligned}
$$

gde je:

- $E_{\text {RES }}$ obnovljiva energija iz vazduha, zemlje ili vode (toplotnog izvora) preuzeta sa strane toplotne pumpe,

- $\mathrm{Q}_{\text {upo- }}$ ukupna korisna toplota koju daje toplotna pumpa,

- $E_{\text {s_ven}_{\text {pumpa }}}$ - energija upotrebljena za pogon ventilatora ili pumpe za cirkulaciju rashladnog fluida,

- $\mathrm{E}_{\mathrm{HW}-\mathrm{hp}}$ - energija za rad same toplotne pumpe,

- $\mathrm{Q}_{\mathrm{H} \_ \text {hp }}$ - toplota isporucena (oduzeta) iz izvora toplote preko toplotne pumpe,

- $\mathrm{Q}_{\mathrm{W} \_\mathrm{hp}}$ - toplota dobijena iz mehanicke energije koja se koristi za pogon toplotne pumpe

Iz granice sistema proizlazi da proračun obnovljive energije dobijene od toplotne pumpe zavisi od same toplotne pumpe, a ne od sistema za grejanje u čijem sastavu je toplotna pumpa. Neefikasno korišćenje energije toplotne pumpe stoga je pitanje energetske efikasnosti, i zato ne utiče na proračun obnovljive energije isporučene od strane toplotne pumpe.

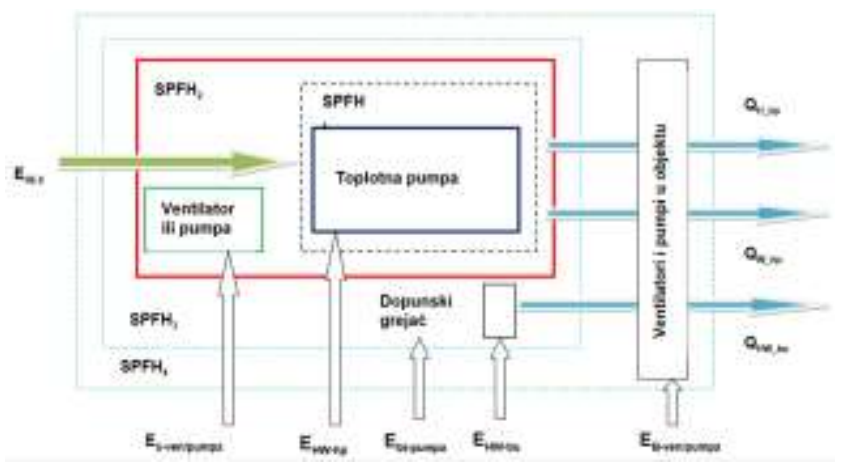

Slika 2. Energija toplotne pumpe [5]

Ako se toplotna pumpa poredi sa drugim izvorima toplote za grejanje, onda njena potrošnja primarne energije, npr. električne energije, iznosi $25 \%$ do $30 \%$ u odnosu na druge sisteme za grejanje (slika 3). Za pogon toplotne pumpe najčešće se koriste elektromotori. Toplotne pumpe sa elektromotornim pogonom mogu da obezbede temperature vode do $75^{\circ} \mathrm{C}$.

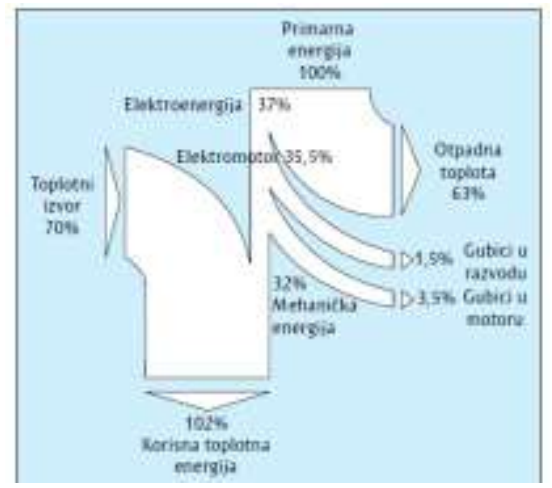

Slika 3. Energetski bilans toplotne pumpe [6]

Kako se povećava temperaturna razlika između ulaza $\mathrm{i}$ izlaza toplote, podrazumeva se da je potrošnja kompresora koja je potrebana za njegovo napajanje veća, pa se COP smanjuje. Stoga je važno razumeti temperaturu za koju je predviđena toplotna pumpa i opseg temperature u kojoj će se koristiti toplotna pumpa.

Prema projektu "WP-Effizienz" [4] sprovedenom od 2005. do 2010. godine je merena potrošnja energije i efikasnost toplotnih pumpi u stambenim objektima. Podno grejanje je bilo najčešci tip sistema distribucije toplote. Prosečna potrošnja grejanja u ovim objektima $u$ 2009. godini iznosila je $72 \mathrm{kWh} / \mathrm{m}^{2}$ za prosečnu površinu grejanja površine $199 \mathrm{~m}^{2}$.

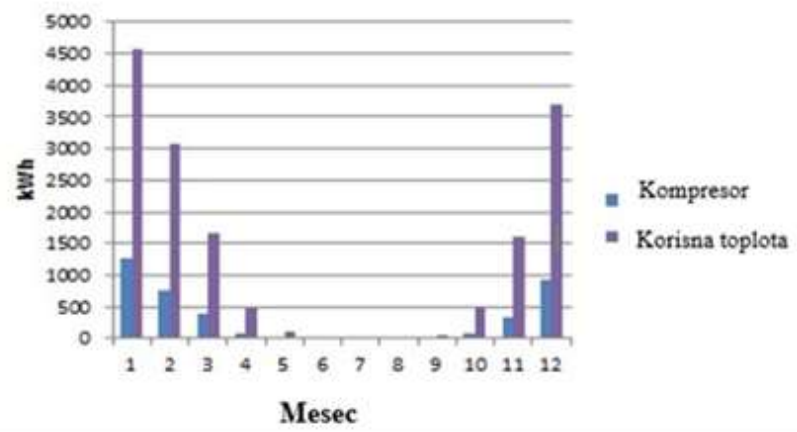

Slika 4. Potrošnja kompresora i dobijena toplotna energija [4] 
Studija je ilustrovala dobar primer potrošnje energije toplotne pumpe i energetsku efikasnost. U samoj studiji dobili smo da se na osnovu ispitivanja i merenja za jednu godinu, da za malu ulaznu energiju, koja se troši na pokretanje kompresora, dobijamo dosta veću izlaznu toplotnu energiju kao što je prikazano na slici 4. Efikasnost toplotne pumpe obično se prikazuje tako što za svaki $1 \mathrm{~kW}$ električne energije, koji se potroši za pokretanje kompresora dobije preko $3 \mathrm{~kW}$ toplotne energije, dajući "efikasnost" od $300 \%$ i više. Termodinamički je nemoguće imati efikasnost veću od $100 \%$, jer bi to podrazumevalo da se proizvede više energije nego što ulazi u sistem.

\section{PROJEKTOVANJE TOPLOTNIH PUMPI}

Sa revolucijom informacionih tehnologija došlo je do razvoja raznih softvera za modelovanje i odabir toplotnih pumpi. Preko softvera se može simulirati rad toplotnih pumpi. To znači da su važni radni parametri izračunati na osnovu raznih standarda u projektovanju objekata i toplotnih pumpi prema preporukama od proizvođača. Postoji veliki broj dostupnih softvera za proračun toplotnih pumpi a najpopularniji su :

GeoT*SOL program, HOMER Pro, The Easy RSS Heat Pump Design, Polysun Simulation Software, RETScreen, Heat Pump Pre-Screening Tool, ETU Software GmbH, TRACE 700, Ground Loop Design GLD, GLHEPRO, Geo Hourly

GeoT*SOL program je specijalizovani alat za planiranje i projektovanje sistema toplotnih pumpi. Dinamična simulacija u toku godine daje sledeće parametre za izabrani sistem toplotne pumpe:Godišnji koeficijent performansi za toplotnu pumpu, gde je to pogodno, solarnu frakcija, količinu energije koju generišu toplotna pumpa na godišnjem nivou, godišnju električna energija potrebnu za toplotnu pumpu, godišnju generisanu energiju za toplotnu pumpu i solarni ciklus, godišnje gubitke rezervoara i cevi za skladištenje, rezime finansijske analize sa svim parametrima i rezultatima, kao i korisne grafike.

HOMER Prosoftver predstavlja globalni standard za optimizaciju dizajna u svim sektorima. HOMER obavlja tri osnovna zadatka: simulaciju, optimizaciju i analizu osjetljivosti. HOMER eksplicitno ne modeluje toplotnu pumpu, ali jednostavno može modelovati i simulirati električno opterećenje na toplotnoj pumpi i dodati to primarnom električnom opterećenju ili ga odrediti kao drugo primarno opterećenje.

The Easy RSS Heat Pump Design je softver za dimenzionisanje i specifikaciju sistema toplotnih pumpi. Easy RSS Heat Pump dizajn softver uključuje:

Određivanje veličine toplotne pumpe, izbor rezervnog izvora, izlaz sertifikata usklađenosti, izračunavanje buke, dimenzioniranje podzemne petlje, izračunavanje troškova, izračunavanje RHI

Polysun Simulation Software je idealan alat za projektovanje solarnih, toplotnih i fotonaponskih sistema, kao i kombinovanih sistema. Softver uključuje proračun ekonomske održivosti, omogućava i na osnovu projektovanog dizajna se dobija proračun ušteda. U softver su integrisani svetski vremenski podaci na osnovu koji se proračunavaju pouzdane simulacije.

RETScreen softver predstavlja program upravljanja obnovljivim izvorima energije za analizu izvodljivosti energetske efikasnosti kao i tekuće analize energetskih performansi. Program, dostupan svima besplatno, može se koristiti širom sveta za procenu proizvodnje energije i ušteda, troškove tokom životnog veka projekata, smanjenje emisija, financijsku isplativost i rizike za razne tipove tehnologija energetske efikasnosti i tehnologija obnovljive energije.

Heat Pump Pre-Screening Tool je softversko rešenje koje omogućava brzu procenu sistema toplotnih pumpi za određeni skup građevinskih parametara sa minimalnim ulaznim parametrima. HPAC ima za cilj pružanje podrške konsultantima za upravljanje energijom i građevinskim inženjerima u opravdanju sveobuhvatne studije izvodljivosti projekta toplotne pumpe.Program upoređuje opcije sistema za toplotnu pumpu sa predviđenim sistemom HVAC sistema za nove komercijalne i institucionalne građevinske konstrukcije ili glavne naknade. Pruža najbolje opcije na bazi smanjenja emisije staklene bašte.

ETU je softver koji omogućava vremenske simulacija toplotnog ponašanja zgrade i potražnje za grejanjem, na osnovu karakteristika zgrade, profila korišćenja i lokalnih klimatskih uslova. Izračunavanje predviđenih performansi toplotne pumpe. Finansijski obračun uključujući povraćaj investicije. Izmenljive korisničke profili za izračunavanje grejanja i potrebe za toplom vodom. Upoređivanje toplotnih pumpi vazduha/vode, toplotne pumpe vode/vode ili toplotne pumpe zemaljskog izvora/vode.

TRACE 700 je sfotver za dizajn i analizu koji pomaže osobama HVAC-a da optimizuju dizajn sistema za grejanje, ventilaciju i klimatizaciju na osnovu korištenja energije i životnog ciklusa troškova. Softver TRACE 700 omogućava da se uporedie energetski i ekonomski uticaj izbora vezanih za gradnju, kao što su arhitektonske karakteristike, HVAC sistemi, HVAC oprema, toplotne pumpe, korištenje zgrada i finansijske opcije.

Ground Loop Design GLD softver predstavlja integrisan skup moćnih, fleksibilnih i prilagodljivih alata za projektovanje komercijalnih i stambenih zatvorenih petlji za sisteme toplotne pumpe. GLD omogućava dizajneru da brzo i tačno:

Odrede dinamičku mehaničku opremu, izračuna zahteve za bušenje/iskopavanje, odredi dužine cevi, vrste i izglede, optimizujte konfiguracije cevovoda, obezbedi efikasnu cirkulacionu pumpu, dizajnira optimizovani i stabilan sistem, proceni troškove životnog ciklusa, predvidi emisiju CO2

GLHEPRO se koristi kao pomoć u dizajniranju vertikalnih izmenjivača toplote sa zupčastom bušotinom. Zahteva tri osnovna skupa ulaznih podataka: opterećenje mesečnog grejanja i hlađenja na toplotnoj pumpi, opis izmjenjivača toplote sa zateznom petljom - uzorak, radijus bušotine i dubinu bušotine, performanse toplotne pumpe sa zadanim vrednostima.

Kada se unesu svi ulazni podaci, GLHEPRO će izvršiti simulaciju ili odrediti dubinu bušotine. 
Nakon toga je prikazan kratak rezime rezultata. Program sadrži detalje o dizajnu petlje i minimalne i maksimalne temperature fluida koje ulaze u bušotine.

Geo Hourly je softver za stambeni i komercijalni geotermalni dizajn za modelovanje petlji u zemlji, analize troškova energije, hibridni dizajn kao i solarni dizajn. Softver omogućava jednostavnu optimizaciju analitike s kojom možemo dobiti operativne troškove nasuprot dizajnu petlje. Mogu se postaviti razni dizajni na osnovu realnih uslova rada što kao posledicu može smanjiti realnu cijenu sistema.

\section{ELEKTRIČNA ENERGIJA I GREJANJE POSLOVNE ZGRADE TOPLOTNOM PUMPOM}

Novosagrađena poslovna zgrada u Bijeljini ima ukupnu površinu poslovnog prostora od $2.000 \mathrm{~m}^{2}$. Nasuprot konvencionalnom sistemu grejanja gasnim kotlom koji godišnje troši $28.781 \mathrm{~m}^{3}$ prirodnog gasa ili $204 \mathrm{MWh}$ energije grejanja, plan je da se instalira sistem bušotinskih izmenjivača toplote odnosno geotermalna toplotna pumpa. Zgrada će, zbog veće termodinamičke iskoristivosti, imati sistem podnog grejanja (niskotemperaturno grejanje) te sistem prisilne konvekcije za potrebe hlađenja. Za kompletni tehnoekonomski proračun odabran je programski paket RETScreen koji sadrži sveobuhvatnu svetsku bazu podataka proizvođača toplotnih pumpi i klimatoloških parametara [3].

Za klimatološke prilike grada Bijeljine proračunate su veličine stepen dana grejanja (pri nominalnoj vrednosti temperature od $16^{\circ} \mathrm{C}$ ) te na temelju podataka o tipu i termalnim karakteristikama tla, geotermalnom gradijentu, te ukupno potrebnoj instaliranoj snazi za pokrivanje vršne potrošnje u ciklusu grejanja, proračunata je potrebna dubina bušotinskog izmenjivača toplote.

Predloženi sistem grejanja toplotne pumpe s bušotinskim izmenjivačem toplote prema programskom paketu RETScreen [3] ima sledeće karakteristike:

- Potrebna zemljana površina oko zgrade: $613 \mathrm{~m}^{2}$

- Ukupno potrebna dubina izmenjivača toplote: $2.115 \mathrm{~m}$ (15 bušotina $\times 141 \mathrm{~m}$ )

- Snaga cirkulacijske pumpe: $3,2 \mathrm{~kW}$

- Volumen vode u izmenjivaču toplote: $0,37 \mathrm{~m}^{3}$

- Potreba dužina polietilenskih cevi izmenjivača: $4.231 \mathrm{~m}$

- Cena goriva (električna energija): 51,0 €/MWh

- Ukupni kapacitet grejanja odabranog modela toplotnih pumpi: 129,0 kW (104\% pokrivene vršne potrošnje)

- Ukupna ostvarena godišnja energija grejanja: 204 MWh (100\% pokrivene ukupno godišnje potrebne energije)

- Stepen iskorištenja toplotne pumpe: $\mathrm{COP}=5,79$

- Proizvođač i model: Viessmann Gmbh, Vitocal300 WW232 (3 jedinice) [1]

- Utrošena godišnja el. energija kompresora: 35,2 MWh

- Godišnji trošak električne energije: 1795,2 €

Kada se uporedi isplativost sistema grejanja sa toplotnom pumpom u odnosu na konvencionalni sistem grejanja na prirodni gas dolazi se do informacije da sistem sa toplotnom pumpom ima bolju isplativost. U sistemu sa konvencionalnim sistemom grejanja je za godinu dana potrošeno 204,0 MWh energije dok je preko sistema sa toplotnom pumpom za grejanje potrošeno 35,2 $\mathrm{MWh}$ električne energije. Finansijski prikazano za konven- cionalni sistem imamo godišnju potrošnju od $9.843 €$ (za cenu gasa $0,342 € / \mathrm{m}^{3}$ ) dok za sistem za toplotnom pumpom potrebno $1.795,2 €$, što predstavlja veliku uštedu. Ipak, treba napomenuti da sistem troši dosta električne energije za pogon kompresora (35,2 MWh), odnosno u proseku oko $3.000 \mathrm{kWh}$ mesečno, što zahteva posebnu instalaciju, pa ima dodatne troškove (angažovana snaga, posebna tarifa i sl.).

\section{ZAKLJUČAK}

Toplotne pumpe smatraju se jednim od najučinkovitijih uređaja za dobijanje toplotne energije, a često se upotrebljavaju u bogatijim zemljama s razvijenom visokom ekološkom svešću. Važan podsticaj u razvijenim zemljama je i uređeno zakonodavstvo, pre svega na području obnovljivih izvora energije, te državna podrška za obnovljivim izvorima energije. U BiH takve podrške za toplotne pumpe još ne postoje, a niti zakonodavstvo nije uređeno na tom području.

Cene sistema s toplotnim pumpama u $\mathrm{BiH}$ su na žalost još uvek jako visoke. Razloga ima više, a oni najizraženiji su: nedostatak državnih podsticaja za primenu obnovljivih izvora energije, relativno visoke cene uređaja i radova koje su rezultat malog broja proizvođača toplotnih pumpi i edukovanih izvođača radova. Bez obzira na brojne poteškoće i nelogičnosti u sistemu, toplotne pumpe ipak i u BiH doživljavaju sve veću ekspanziju. U razvijenim zemljama Evrope obnovljivi izvori energije zauzimaju značajno mesto u energetskoj politici. Za očekivati je da će se i kod nas težiti istom trendu. Do tada, ušteda energije i zaštita životne sredine primenom obnovljivih izvora energije ostaje na nivou razvijenosti naše savesti i na našim financijskim mogućnostima.

\section{LITERATURA}

[1] https://www.viessmann.rs/

[2] R. Bertani, „Geothermal Energy: An Overview on Resources and Potential",Inter.Conf.on National Development of Geothermal Energy Use, Slovakia, 2009

[3] RETScreen, http://www.retscreen.net/,Canada

[4] https://www.ise.fraunhofer.de/en/researchprojects/wp-monitor.html

[5] http://kgh-kongres.rs/index.php/en/

[6] https://www.automatika.rs

\section{Kratka biografija:}

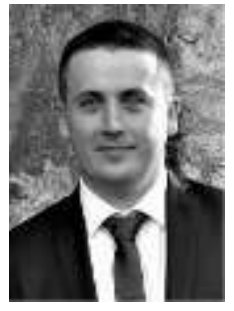

Branko Adžić, dipl.ing. rođen je 1987. god. u Sarajevu. Srednju tehničku školu Mihajlo Pupin, završio je u Bijeljini, 2006. god. Fakultet tehničkih nauka, studijski program Energetika, elektronika i telekomunikacije (OAS) upisao je školske 2006/2007. Na studijama se opredelio za modul Elektroenergetika-energetska elektronika i električne mašine i diplomirao 2012. god. Kontakt: adzicbranko@gmail.com 